\title{
A sustainability index for offshore wind farms and open water aquaculture
}

\author{
G. Benassai ${ }^{1}$, C. Stenberg ${ }^{2}$, M. Christoffersen ${ }^{2} \&$ P. Mariani ${ }^{2}$ \\ ${ }^{1}$ Department of Applied Sciences, University Parthenope, Naples, Italy \\ ${ }^{2}$ National Institute of Aquatic Resources, \\ Technical University of Denmark, Lyngby, Denmark
}

\begin{abstract}
One of the possible multi uses of marine space is offshore wind farms and open water aquaculture plans. Unlike coastal installations, offshore wind farms allow for increased availability of wind power and wind persistence, as well as lower visual impact of the turbines. Existing offshore wind farms offer important advantages for aquaculture plans especially in terms of lack of major physical constrains, e.g., navigation routes, submarine cables, marine protected areas. Moreover, enhanced current velocity due to the presence of the piles and to the air fluxes of the turbines may increase the environmental suitability of aquaculture plans in these areas. In addition, the transmission of localized depleted water masses or waste material towards near-shore zones can be avoided, excluding potential impact close to the coast. On the other hand, other environmental constrains (e.g. temperature and salinity variability, dissolved oxygen concentrations, phytoplankton dynamics) need also to be considered when planning aquaculture activities.

In this context, the present paper gives a contribution towards the definition of a sustainability index for the large scale localization of marine areas as offshore wind farms and aquaculture plans. This index is developed on the basis of a Multi-Criteria Evaluation (MCE) technique, already used in open water aquaculture localization: raw data were converted to suitability scores, which were combined using additive models, in order to define the overall suitability. A detailed analysis of the environmental suitability is performed for few specific test cases at offshore wind farms located in the Denmark coastal zone, for which some projects of offshore aquaculture plans have been proposed.
\end{abstract}


The use of this sustainability index will perform quantitative evaluations of the degree of compatibility between the offshore wind farms and the open water aquaculture, highlighting the main problems which can rise by the integration of both technologies.

Keywords: sustainability index, offshore wind farms, open water aquaculture.

\section{Introduction}

Compared to onshore wind, offshore wind farms are more costly to install and maintain but also have a number of key advantages: stronger and more stable wind; larger wind turbines; less conflict with neighbouring citizens and other stakeholders unless they interfere with competing maritime activities or impact negatively on important marine environmental interests.

In Europe, over $100 \mathrm{GW}$ of offshore wind projects are already in various stages of planning [1]. If realised, these projects would produce $10 \%$ of the EU's electricity whilst avoiding 200 million tonnes of $\mathrm{CO}^{2}$ emissions each year. There are currently 830 wind turbines now installed and grid connected, totalling 2,063 MW in 39 wind farms in nine Northern European countries. During 2009, 201 wind turbines installed and grid connected totalled 584 MW, up 56\% from 2008 installations [1].

Several large projects are planned in other countries, including Southern Europe where wind energy productions are not as mature as in the Northern European Countries [2]. In Italy, Enel (national body for the electric energy) deposited the project design for one of the first offshore wind farms in the Mediterranean Sea, proposing the installation of 115 large generators with a capacity between 3 and $5 \mathrm{MW}$ in the waters of the Gulf of Gela. Moreover, another offshore wind project is based on floating wind turbines in higher depths (more than $110 \mathrm{~m}$ ), located $20 \mathrm{~km}$ offshore the Apulia coastline (Tricase offshore wind farm) [2]. This project follows the technology of Hywind project in Norway (see http://www.statoil.com/en/technologyinnovation/newenergy/ renewablepowerproduction/onshore/pages/karmoy.aspx).

The overall high-competitive use of the coastal zones highlights the need to optimize co-management of the resources, which raises some advantages in the potential combination of marine space utilization. Many of the smaller wind farms are located relatively close to the shore $(<5 \mathrm{~km})$ while the larger parks are positioned more offshore $(>20 \mathrm{~km})$. The trend seems to be bigger turbines and parks and more offshore position. An example of this is the Dogger Bank wind farm which is on the drawing board these years. This park is planned to be on $9000 \mathrm{MW}$, consist of more than 1500 turbines, cover an area of $2000 \mathrm{~km}^{2}$ and is to be $200 \mathrm{~km}$ from the shore.

The most used foundations for the turbines are monopile and gravity ones. In order to prevent sediment erosion large boulders are placed around the monopile turbine for scour protection. While windmills use the wind above the surface to produce energy, their fixed pylons may offer a basis to connect systems used in aquaculture or create artificial nursery areas for wild fish species. Additionally, 
the multi-use concepts of these two industries can assist to avoid user conflicts with fishermen, who may lose part of their traditional fishing grounds [3].

The advantage of moving aquaculture further away from coastal waters consists in an enhanced water quality. Open ocean waters are in general less exposed to anthropogenic impacts and might provide a continuous supply of clean water having satisfactory levels of dissolved oxygen and minor concentrations of pollutants, pesticides and near-surface agents. However, open ocean hydrodynamic conditions can represent further challenges for aquaculture infrastructures and require resistant species that can withstand strong currents and large wave heights. There are however candidates [4] that can be cultivated in these conditions, such as blue mussels. The growth of these mussels is largely controlled by food availability and phytoplankton dynamics. Several studies have identified strong direct linkage $\left(\mathrm{R}^{2}=0.77\right)$ between upwelling indices and cultured shellfish production and quality [5]. In fact upwelling typically provides a rich source of nutrients to enhance phytoplankton growth and large volumes of shellfish are cultured in areas of high phytoplankton concentrations. Sea surface Chl-a concentrations is often considered a good proxy to identify areas of high biological production [6].

Biological productivity in marine areas is generally the result of oceanographic processes such as upwelling, gyres or eddies, which can transport cold, nutrient-rich water from below the pycnocline to the euphotic zone where photosynthesis of autotrophs organisms takes place. The cold water signature of the nutrient-rich water in these productivity hot spots is typically associated with low SSTs. The spatial integration of normalized SST and Chl-a anomalies indicates areas of productive processes such as upwelling, gyres, etc. [5, 6]. The use of climatological (long-term) datasets allow the identification of persistently productive regions, independent of short-term variability.

\section{Methods and data}

\subsection{Structure of the SI}

We defined the Sustainability Index (SI) as the geometric mean of all environmental indexes relevant to our study. Those environmental indexes were based on climatological values of: sea surface temperature (SST), chlorophyll concentration, topography, wind power and SST anomalies [8] which are then modified by their Parameter Specific Suitability Functions and subsequent restrictions by the Boolean constraints layer:

$$
S I=\prod_{i=1}^{n} P S S F_{i}
$$

The Parameter Specific Suitability Function (PSSF) for each environmental data map was defined on an arbitrary scale between 0 and 1 , where 0 defined a non-suitable area and 1 the most suitable. The Boolean constraints layer allows an element to belong to a 'crisp' set (0 or 1) taking into account the existing technology and environmental restrictions. 


\subsection{Environmental data}

Depth data in the North Sea area were derived from ETOPO2 seabed topography (Figure 1) which showed a quite shallow and uniform depth in the southern part of the basin and along the entire coastline. In particular close $(<30 \mathrm{Km})$ to the Danish coast, depth was always lower than 20-25m.

The Sea Surface Temperature (SST) and SST anomalies in the North Sea (Figures 2 and 3) were obtained from the Advanced Very High Resolution Radiometer (AVHRR) Pathfinder data produced by NOAA and the University of Miami's Rosenstiel School of Marine and Atmospheric Science (http:// pathfinder.nodc.noaa.gov). SST could have ecological consequences on the growth of organisms with higher temperatures allowing faster growth of the aquaculture species. Moreover, additional potential environmental changes in response to changes in SST could be measured as the frequency of temperature anomalies [7]. Data for SST anomalies included anomaly frequency between 2000-2005 and 1985-1990.

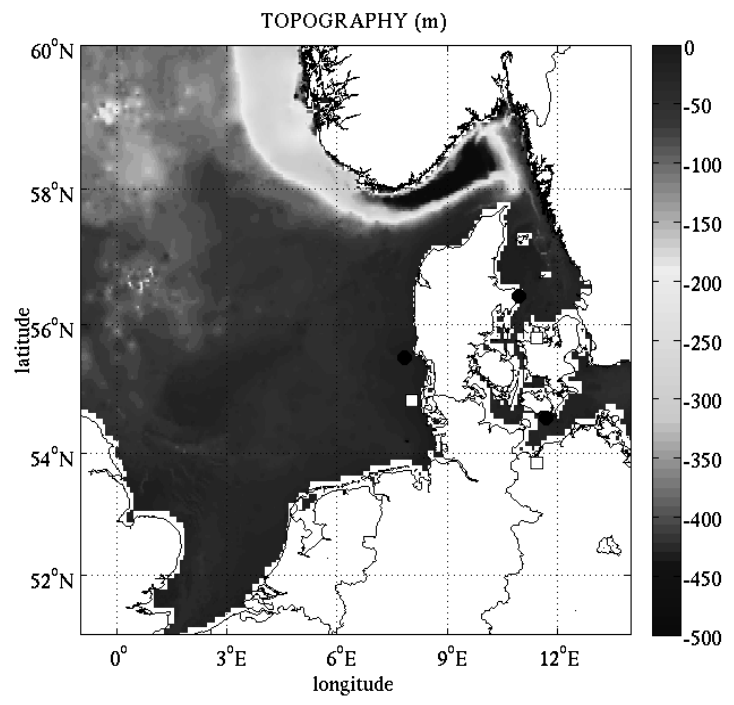

Figure 1: Map of topography in the study area with indication (dots) of the three locations analyzed for multi-use purpose platforms in Denmark.

Those data were derived from Halpern et al. [7] and provided a baseline for determining when temperatures were unusually warm having negative consequences on aquaculture species. Lower anomalies occurred in the SouthEastern part of the North Sea and further East, into the Skagerrak and Kattegat. The Southern and Eastern North Sea, from the German Bight into the Skagerrak, were under the influence of the Jutland current which in the Northern part of Denmark branches into two currents, one staying in the North Sea and the other 


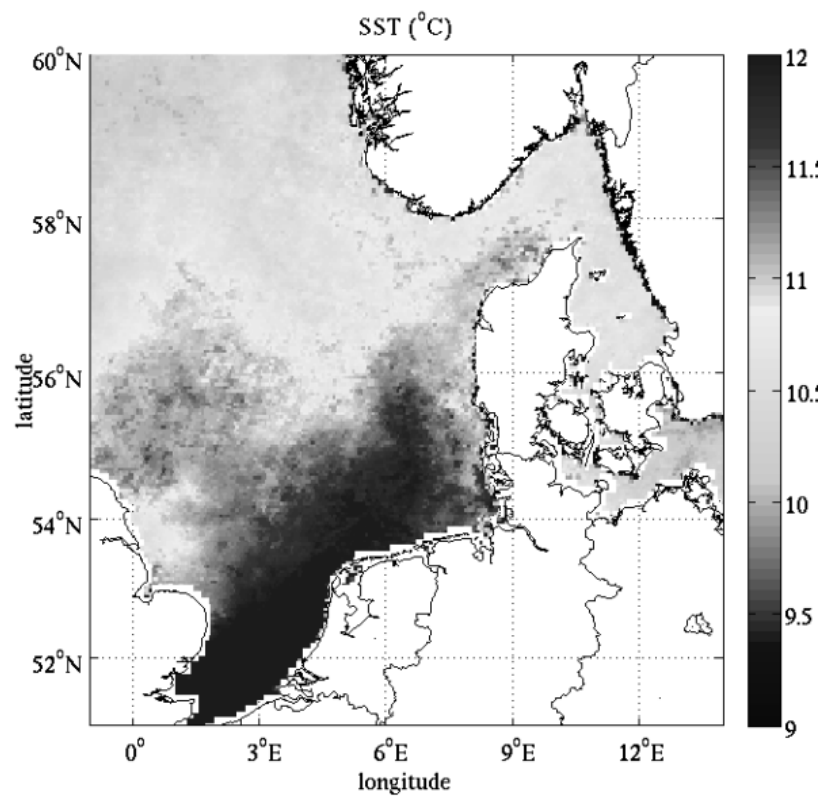

Figure 2: $\quad$ Map of the distribution of Sea Surface Temperature.

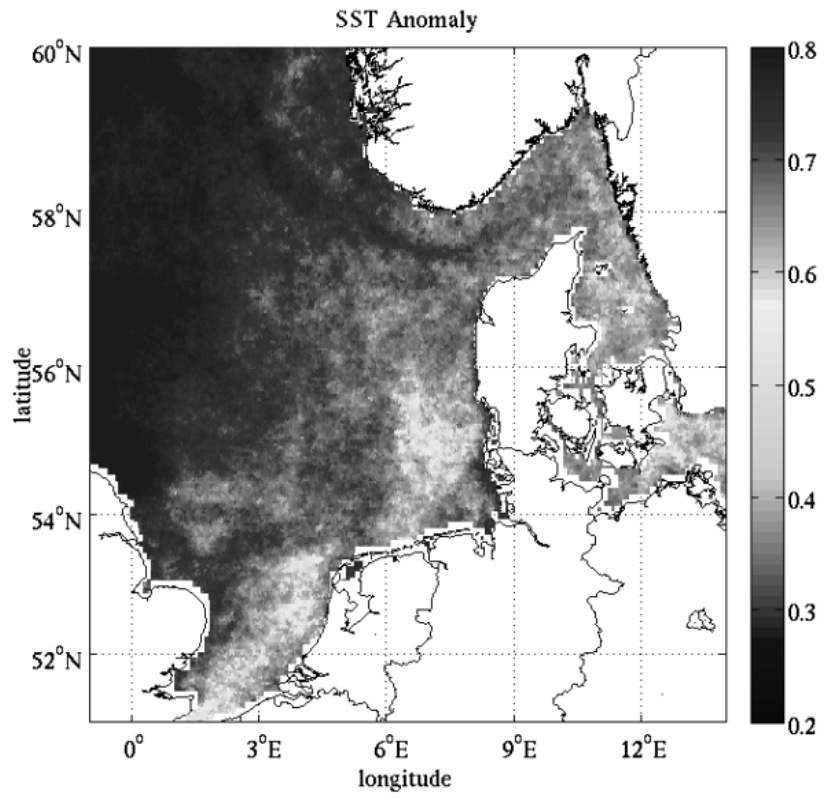

Figure 3: $\quad$ Map of the distribution of SST anomaly. 
entering the Skagerrak. In the Kattegat the influence of oceanic circulation was weaker than in the North Sea since dominating factors were river run-off and larger atmospheric variability above land $[8,9]$.

The Chl-a climatology in the North Sea (Figure 4), exhibited a similar variation: in the South-Eastern part of the North Sea Chl-a was influenced by the shallow water and the strong tidal currents which transported high sediment loads. In general the North Sea circulation was anti-clockwise, so that German Bight waters, which were nutrient-rich due to river discharge in relatively low depth, were transported up along the Jutland west coast, into the Skagerrak and even spilled into the Kattegat [9].

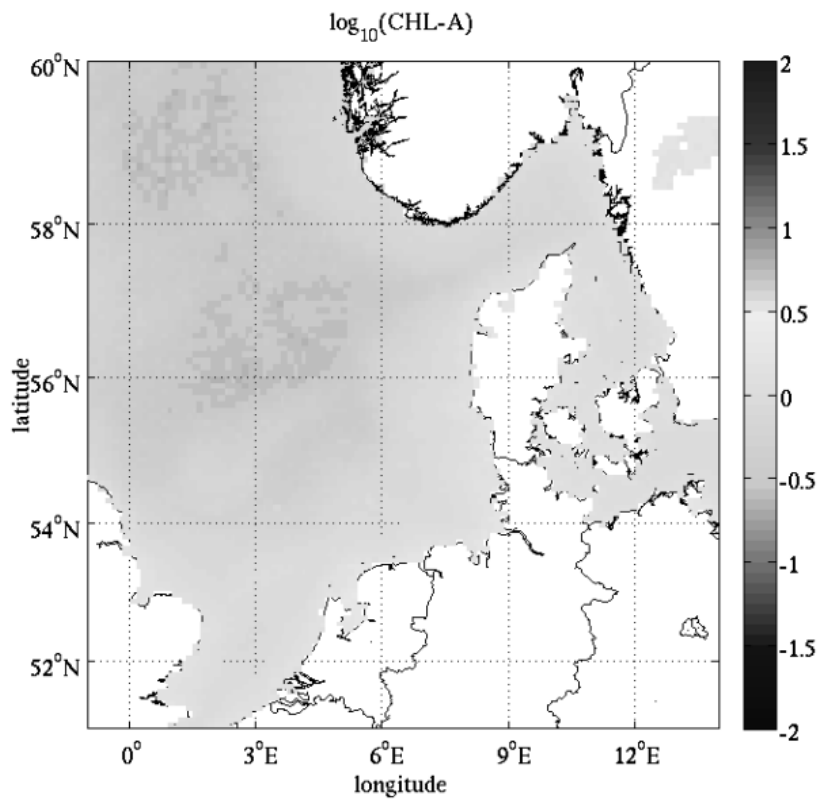

Figure 4: Map of the distribution of chlorophyll-a concentration (in log scale).

Finally, wind speed data were obtained from Scatterometer Climatology of Ocean Winds (SCOW) [10] and were based on a yearly average of climatological monthly values (122 months included) at $\sim 26 \mathrm{Km}$ resolution in the study area (Figure 5). This relatively low resolution did not allow a detailed description of the Kattegat area. In order to have a complete coverage in the definition of the PSSF of the study area we then extrapolated the wind speed values in the Skagerrak into the Kattegat area. The resulting map showed average wind speed ranging between $7-10 \mathrm{~m} / \mathrm{s}$ with higher values in the Northern zones. 


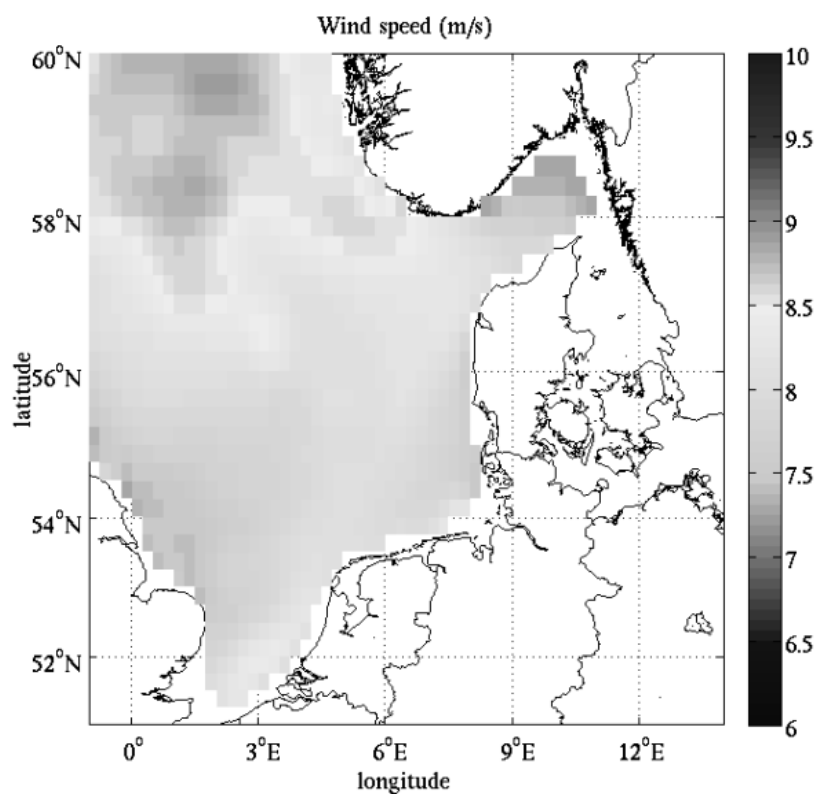

Figure 5: $\quad$ Maps of the distribution of wind speed.

\subsection{Computation of PSSF for offshore wind farms and open aquaculture plans}

Raw data of the environmental conditions described above were re-binned in the study area using relatively high horizontal resolution $(1 \mathrm{Km})$ and nearest values interpolation method. An ad-hoc normalization procedure was then applied to compute the PSSF ranging between 0 and 1.

Topography and wind speed were considered to derive PSSF of the wind farm activities in the North Sea. Due to the different cost percentage between the turbine and the monopile structure in relatively low depths $(<30 \mathrm{~m})$ a step cost function for the depth was assigned, with five steps ranging from below $20 \mathrm{~m}$ (most favourable), to higher than $80 \mathrm{~m}$ (least favourable). A Boolean constraint was assigned to the benthic sediment type, which can be only constituted by sand or gravel, due to the limits of the monopile technology. A conversion between wind speed and energy was obtained using the standard power curve for the Vestas V112, 3MW turbine which was particularly suited for offshore sites [2]. Then a normalization procedure (values/max value) ensured PSSF varying between 0 and 1 . The maximum value of 1 (most favourable) was given to the mean wind speed corresponding to $100 \%$ of the power transfer function $(12 \mathrm{~m} / \mathrm{s})$, while the other PSSF values were assigned consistently. Thus the PSSF was not linear with wind speed but shaped accordingly to the physical energy transfer from the wind. 
SST, SST anomaly and Chl-a were the three environmental factors assumed to affect the PSSF of aquaculture activities. The calculation of PSSF for the SST and CHL-a was made on the basis of a normalization technique over the environmental data (values/max value). Chlorophyll values changed over many orders of magnitude, so in order to weight similarly all the environmental parameters an additional rescaling was applied to the logarithmic $(\log 10)$ of Chl$a$ in order to obtain the PSSF ranging from 0 and 1. The SST anomalies were transformed in anomaly indexes suitable for aquaculture, attributing 1 to low values of temperature anomaly and 0 to maximum positive anomaly, because large SST anomalies are detrimental for aquaculture activities.

\section{Results}

The Suitability Index (SI) for co-location of wind farm and aquaculture plans (Figure 6) showed values ranging between $\sim 0$, in the Northern deepest zones of the study area, and higher values $(0.6-0.8)$ in the Southern part of the North Sea and all around Denmark, with the highest values on the Western coast.

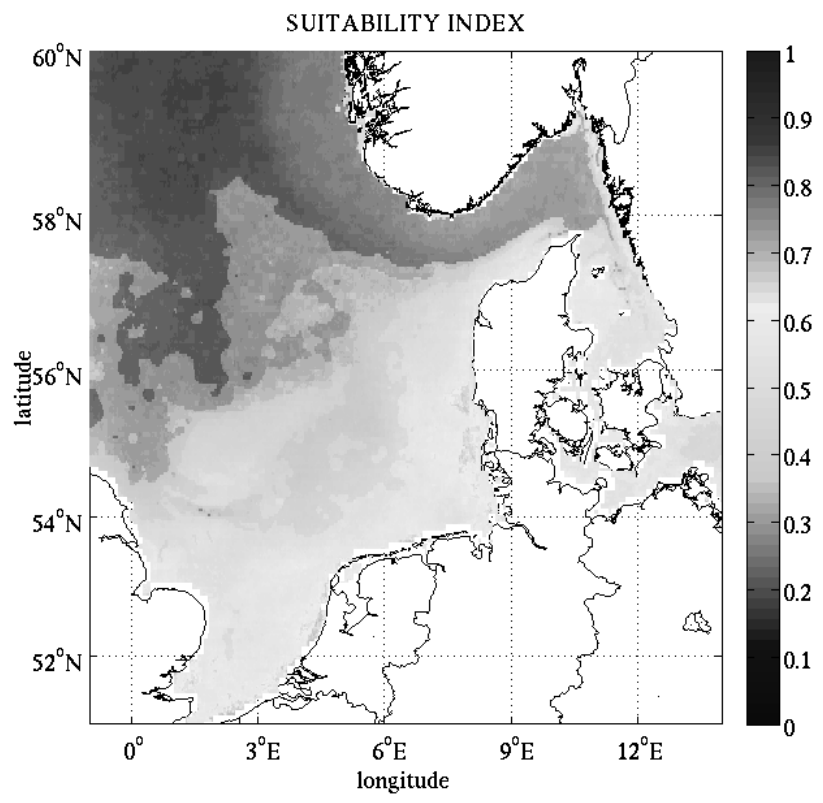

Figure 6: Map of the suitability index for the North Sea and adjacent seas.

As shown in figures 6 and 7, relatively high SI values were also evident in the Central North Sea close to the Dogger bank. The SI appeared to be consistent with shallow areas having high SST and low SST anomalies while Chl-a and wind speed appeared to have a secondary effect due to their relatively uniformity in the study area. 


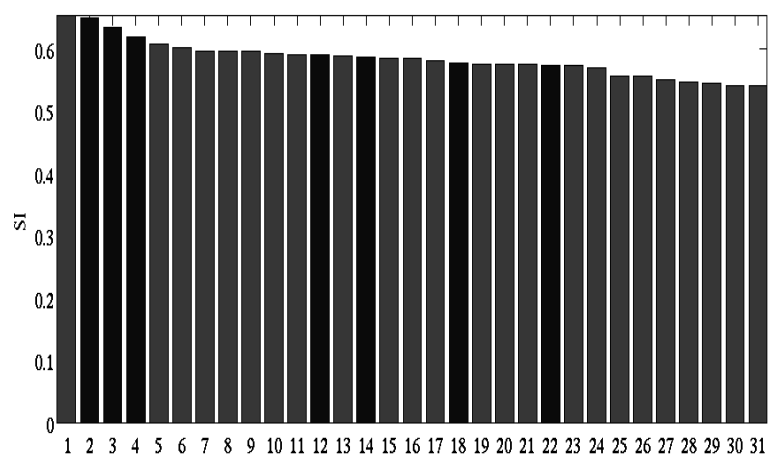

Figure 7: Suitable Index values at the locations (proposed=light grey, operating=dark grey) of Danish offshore wind farm. The highest value is for the proposed location Horn Rev $(7.9 \mathrm{E} 55.7 \mathrm{~N})$, the $2^{\text {nd }}$ and $3^{\text {rd }}$ highest are the Horn Rev1 $(7.8 \mathrm{E} 55.5 \mathrm{~N})$ while the $4^{\text {th }}$ is the Nysted $(11.2 \mathrm{E} 55.0 \mathrm{~N})$. The site called Anholt $(11.3 \mathrm{E} 56.5 \mathrm{~N})$ is at position 23 .

\section{Discussions}

In Denmark several sites were used or planned to be used for offshore wind farms installations (Figure 8). According to our SI most of those sites appeared to be suitable locations for a multi-use purpose combining wind energy and aquaculture activities. The SI defined above provided a first and large scale evaluation of the feasibility of setting aquaculture activities in offshore wind farm sites. However, the index as defined above did not include other relevant aspects which needed to be accounted for in making the aquaculture activity feasible.

Offshore aquaculture has drawn a lot of attention because of the large areas available offshore and thus its huge potential. However, there are today worldwide few, if any, aquaculture facilities that are positioned offshore in exposed conditions. The rough conditions demands special solutions and equipment that at present are not fully developed. Fitting offshore aquaculture into wind farms is another and addition challenge. Operation and maintenance of the turbines requires frequent visits of smaller ships and yearly call of large ship crane [4]. Aquaculture facilities in a WF must therefore adapt to these constrains and challenges. Solutions could be only to occupy a part of the WF area for aquaculture and/or to have mobile facilities that can be towed away when needed.

Stenberg et al. [4] estimated that up to $25 \%$ of the area in a WF could be used for pelagic mussel productions. Another solution for mussels could be to collect mussel seeds elsewhere and use the seafloor in WF for mussel beds thereby avoiding lines, anchors, floats etc in the WF area that are in potential conflict 


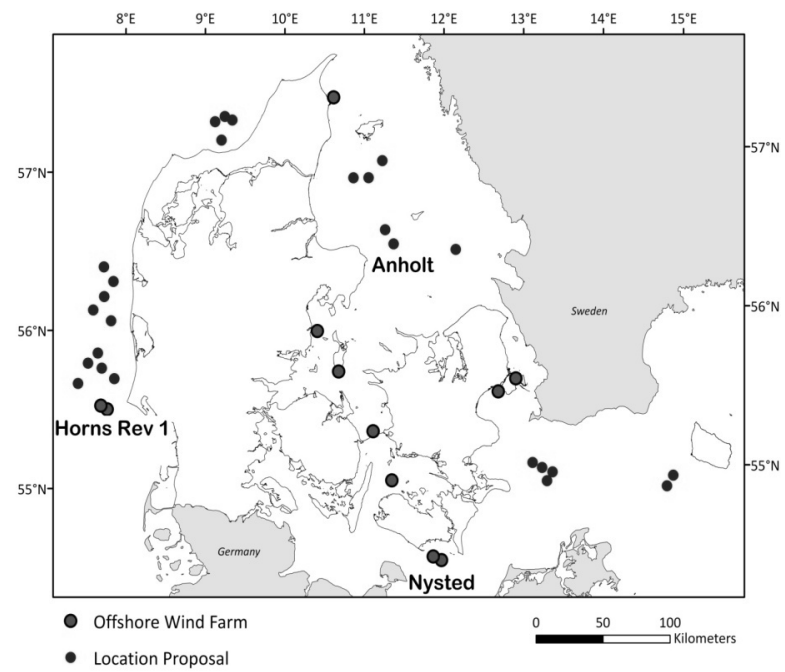

\begin{tabular}{|l|c|c|c|}
\hline Location & Horns Rev 1 & Anholt & Nysted \\
\hline Number of turbines & 80 & 112 & 72 \\
\hline Area covered in WF $\left(\mathbf{k m}^{\mathbf{2}}\right)$ & 27,5 & 88 & 24 \\
\hline Distance between turbines $(\boldsymbol{m})$ & \multicolumn{3}{|c|}{$450-550$} \\
\hline Depth in WF $(\boldsymbol{m})$ & $2-9$ & $14-20$ & $6-9,5$ \\
\hline Sediment type in WF & Sand/gravel & Sand & Moraine/sand \\
\hline Distance to nearest port $(\mathbf{k m})$ & \multicolumn{3}{|c|}{$10-15$} \\
\hline
\end{tabular}

Figure 8: Distribution of offshore WF (operational/proposed) in Denmark.

with other WF activities. An analysis of the economical feasibility is associated with great uncertainty but estimate a break-even price for blue mussels between $1.5-2.0 € \mathrm{~kg}-1$ [4]. The market price in 2010 was less than $1 € \mathrm{~kg}^{-1}$. However, the mussel production from a single WF would be the same as the total production of mussels in Denmark at present. The large scale would probably bring down operating costs thereby reducing the break-even price.

For fish aquaculture, a solution could be smaller cages that are easily moveable and only to farm fish in the growth season (spring to autumn), e.g. juvenile to consumer size fish allowing a time window for turbine maintenance and reducing risk of sea ice damages [11].

Another approach could be to use the WF areas for extensive aquaculture as sea ranching and stock enhancement solutions. A suitable species for this could be the European lobster (H. gammarus). Lobsters are economical valuable and can be artificially raised for release of the juveniles in WF areas. The scour protection around each turbine is believed to be a very suitable lobster habitat for juvenile and adult lobster. Due to lack of suitable habitat in the adjacent areas is hypothesized that the lobsters will remain in the WF area throughout their entire life. This would allow an effective sea ranching concept with harvest 3-5 years 
after the release of the juveniles. An increase in suitable habitat could be combined with innovative cable protection or artificial lobster reefs within the WF.

\section{Conclusions}

The application of MCE technique for co-location of offshore wind farms and open water mussel cultivation was collected in a definition of the Suitability Index (SI), which is a possible response to the actual and future need of a smart tool for multiple marine space utilization. This SI is easily implemented in GIS in order to do a first order selection of the most promising areas to be more specifically studied in a second order approach, to be based on local field data.

The SI defined above provided a first and large scale evaluation of the feasibility of aquaculture activities in offshore wind farm sites. However, the index as defined above did not include other relevant aspects, such as the wave and current loads on the long-lines of mussels. Moreover, the present results rely heavily on the data resolution, which could be probably increased for the wind velocity and the CHL-a which should be extend to values other than the surface. However, the relative comparisons upon which the method is based are susceptible of further on-site detailed studies.

\section{References}

[1] EWEA 2009 Annual Report. http://www ewea org.

[2] Floating Wind Turbines, Deep Water Installation Offshore Industry 2 (4): 48-51. 2009. www.wikipedia org.

[3] Buck B (2004) Extensive open ocean aquaculture development within wind farms in Germany: the prospect of offshore co-management and legal constraints. Ocean and Coastal Management 47: 95-122.

[4] Stenberg C, Christoffersen M, Mariani P, Krog C, Dolmer P, Maar M, Tørring D. ICES Conference 2010 ICES CM 2010: O:12.

[5] Espinosa-Carreon TL, Strub PT, Beier E, Ocampo-Torres F, GaxiolaCastro G (2004) Seasonal and interannual variability of satellite-derived chlorophyll pigment, surface height, and temperature off Baja California. Journal of Geophysical Research-Oceans 109.

[6] Valavanis VD, Kapantagakis A, Katara I, Palialexis A (2004) Critical regions: A GIS-based model of marine productivity hotspots. Aquatic Sciences 66: 139-148.

[7] Halpern BS, Walbridge S, Selkoe KA, Kappel CV, Micheli F et al. (2008) A global map of human impact on marine ecosystems. Science 319: 948952.

[8] Becker GA, Pauly M (1996) Sea surface temperature changes in the North Sea and their causes. Ices Journal of Marine Science 53: 887-898.

[9] EC-FP5 REVAMP (2005) Atlas of Chlorophyll-a concentration for the North Sea based on MERIS imagery of 2003. Project Report 1-121. 
[10] Risien CM, Chelton DB (2008) A Global Climatology of Surface Wind and Wind Stress Fields from Eight Years of QuikSCAT Scatterometer Data. Journal of Physical Oceanography 38: 2379-2413.

[11] Møller and Bregnballe (2009) Assessing the possibilities of establishing mariculture at Nysted (in Danish). 3-26, in: Vurdering af mulighederne for opdræt af fisk og skaldyr i områder med havvindmøller - pilotprojekt Nysted Havmøllepark, editor Carsten Krog 